\title{
TCOM \\ Strategies for including communication of non-Western and indigenous knowledges in science communication histories
}

\section{Lindy A. Orthia}

\begin{abstract}
How a discipline's history is written shapes its identity. Accordingly, science communicators opposed to cultural exclusion may seek cross-cultural conceptualizations of science communication's past, beyond familiar narratives centred on the recent West. Here I make a case for thinking about science communication history in these broader geotemporal terms. I discuss works by historians and knowledge keepers from the Indigenous Australian Yorta Yorta Nation who describe a geological event their ancestors witnessed 30,000 YBP and communicated about over generations to the present. This is likely one of the oldest examples of science communication, warranting a prominent place in science communication histories.
\end{abstract}

Keywords

History of public communication of science; Science communication in the developing world; Social inclusion

DOI

https://doi.org/10.22323/2.19020202

Submitted: 10th October 2019

Accepted: 13th March 2020

Published: 30th March 2020

Introduction

Conceptualization of a discipline's past is important for forging disciplinary identity in the present. As Dayé [2018] argues for sociology, disciplinary histories can strengthen a sense of community among members. Conversely, histories may also exclude potential members. Histories help members and others critically reflect on the discipline's place within society and the extent to which 'its leading ideas are socially determined by the cultural, economic, and political positions of its members' [Dayé, 2018, p. 532]. Histories thus help set agendas, and can aid or hinder disciplinary reform.

As such, it matters how science communication researchers, teachers and practitioners conceptualize their collective past. For example, it matters that science communication's origins are generally characterized as Western and recent, as I outline below. It matters because, at present, science communication is a global 
discipline, with practitioners and researchers hailing from across the world. ${ }^{1}$ Science communication also features prominently in the cultural infrastructure of countries with diverse multicultural populations, such as Australia and the U.K. Histories of science communication whose boundaries are drawn at the recent West may reinforce the ongoing marginalization of minoritized and racialized peoples within this discipline and its cultural endeavours. Questioning how such histories are written is therefore warranted.

There is strong evidence that Eurocentric values in science communication practice and scholarship contribute to marginalization and inequity in Australia and the U.K. (and likely in similar countries), and that countering Eurocentrism can help redress this. Dawson [2019] describes systemic Eurocentrism in U.K. science museums and other science communication endeavours, and documents the profound, multi-faceted, exclusionary impact this has on people who belong to minoritized ethnic groups. Looking at Australian science outreach centres, Perera [2014] found orienting activities towards relevant cultural contexts to some extent mitigated this kind of exclusion among recently arrived refugees from Asian and African nations. Gondwe and Longnecker [2015a] demonstrated a division between young Australians' ideas about 'science' and 'culture' respectively, and argued for diverse, culturally nuanced representations of science and technology in museums and elsewhere to redress this. In imagining a more inclusive future for Indigenous Australians within science, Ball [2015, p. 19] envisaged both that Indigenous adults will run science-engagement activities to effectively mentor Indigenous youth, and that 'Indigenous scientific and engineering heritage will be researched, documented, taught and celebrated by Indigenous and non-Indigenous scientists and historians.' Morrison and colleagues [2019, p. 23] echoed this, stating, 'Decolonisation can only advance when Indigenous knowledges and knowledge practices are acknowledged and validated by a nation's cultural institutions, such as schools and universities.'

My own experience that prompted this paper concerned Chinese nationals enrolled in an Australian university course about science communication history. Some students felt more included, validated and professionally enabled when freed to engage with centuries-old Chinese examples of science communication in assessment, despite these examples being far removed from conventional historical definitions of 'science communication'. Insofar as access to science communication facilitates social power, a desire to radically democratize ownership over it may be served by conceptualizing its history as bigger than the West and older than recent centuries, if such a move is justifiable. Since this research field is still in relative infancy, it is timely to intervene now.

In this paper I explore how this might be possible. My argument proceeds in four parts. First, I review dominant trends in science communication historiography including its characterization of the discipline as Western and recent. Next, I draw parallels with histories that characterize science as Western and recent partly on terminological grounds, and discuss pragmatic political reasons for challenging these. I then engage with arguments against superficially incorporating indigenous and other non-Western knowledges within the categories 'science' or 'science

\footnotetext{
${ }^{1}$ Science communication is at least a well-developed and increasingly coherent field which may be forming a discipline [Rauchfleisch and Schäfer, 2018]. I use the word 'discipline' for clarity, to differentiate it from the field of science communication history.
} 
communication'. Finally I propose moves for working towards very long term, cross-cultural histories of science communication.

I illustrate this final point with an example of science communication that is likely among the oldest in the world. It is a story about a geological event that occurred c.30,000 years ago and was witnessed by ancestors of the Indigenous Australian Yorta Yorta Nation. It was transmitted through generations and is still told by Yorta Yorta people today. Reconceptualizing science communication history to (respectfully and appropriately) include this and similar examples may help science communicators dismantle their discipline's infrastructures of exclusion while respecting the truths of the past.

The historiography of science communication
The history of science communication is a relatively new research field with roots in history of science. Partly because of this foundation, most current conceptualizations of science communication history are geographically, culturally and temporally narrow. Much research has examined the ways establishment science was popularized, and popular science 'by the people' developed, in Western Europe during the nineteenth and twentieth centuries, especially in Britain and France [Topham, 2009b]. Historical research about similar activities in other places is much less developed, including other parts of Europe and Anglophone colonies, but especially elsewhere in the world [Daum, 2009; Pandora, 2009; Papanelopoulou, Nieto-Galan and Perdiguero, 2009]. Where it does exist, it almost always concerns relatively recent history associated with the spread of Western-style science beyond the West, rather than other forms of science and knowledge-making [e.g. Fróes da Fonseca, 2017; Massarani, Moreira and Lewenstein, 2017; Raza and Singh, 2009]. If a history extends further back through time, it is most likely to be related to the so-called Scientific Revolution [Gil, 2018; Mazzotti, 2004; Meyer, 2016] or to incorporate Ancient Greek philosophy [Bensaude Vincent, 2001], in concert with the Eurocentric tradition that sees the Greeks' work as the most important precursor of Western science [Hobson, 2004]. Exceptions - such as Leach's [2013] brief inclusion, in her historical overview, of early Chinese communication about gunpowder - are rare. Consequently, attention to science communication history is often pulled towards the well-studied cultures, making it hard to conceive of science communication beyond the recent West.

Related to that, historians have strongly tied key terms such as 'science popularization' and 'popular science', to specific recent, Western cultural developments. Bensaude-Vincent [2009, p. 367] elaborated on the reasons:

Popular science is a transient and contingent notion, characteristic of the nineteenth- and twentieth-century science that saw scientific practices gradually confined into academic spaces and thus configured the 'public' as passive spectators or users of its products. This notion cannot be extrapolated either to earlier periods (when amateur practices of science were legitimate) or to more recent history (when technoscience is open to the market and permeates our daily life). 
Or in the words of Topham [2009b, p. 313]:

Taken as actors' categories, the diverse international lexicons of 'popular science,' 'science populaire,' and 'Populärwissenschaft' (to mention just three linguistic variations) have been used to organize scientific activity and discourse for barely two centuries. They are unmistakably phenomena of modern times.

Certainly, these terms have recent historical origins, and it is historians' role to place them and their associated practices in historical and cultural context. However, the terms are also used in the present as synonyms of 'science communication' and similar concepts as any search of journals in this realm will attest. Scholars like Bensaude-Vincent [2009] may differentiate between them; for example she uses 'science communication' as a generic in contrast to the specific others. Nonetheless they are discursively and genealogically linked, as Govoni [2009, p. 24] noted:

using the expression 'popular science' in English today means referring to the awareness of the existence of a longstanding tradition of relationships - not always easy, but at any rate uninterrupted in two and a half centuries - between science and the public.

These links exist partly because institutions we might consider essential components of science communication today - professionalized science and the bourgeois public sphere - became institutionalized in Western Europe around the late eighteenth-early nineteenth centuries [Cunningham and Williams, 1993; Habermas, 1989]. Further, researchers have traced origins for many mediums and modes of present-day science communication to the same time and place, including public science lectures and demonstrations [Bensaude-Vincent and Blondel, 2008; Huang, 2016; Lynn, 2006], publicly accessible museums [Knight, 2006], mass-produced science-themed periodicals [Bensaude Vincent, 2001; Mori, 2016; Sheets-Pyenson, 1985], expert-to-public risk communication [Ampollini, 2018] and questions about the role of science in democratic policy-making [Orthia, 2016a]. Crucially, these 'origins' are recognizable because of this coincidence of the three elements: familiar communication methods, content produced by professionalized science or in conversation with it, and the nominal audience being some version of 'the public'. So science popularization and popular science from Western Europe c. $1800 \mathrm{CE}$ seem the most obvious, and perhaps the only legitimate, progenitors of present-day science communication.

In contrast, it would seem simple-minded, anachronistic and/or culturally imperialistic to label all the communication of knowledge across the world before 1800 as 'science communication'. Anachronism is not easily defensible, hence historians write histories in terms of local actors' categories and worldviews. Similarly, the elision of cross-cultural differences through universally applying Western frameworks to non-Western cultures is hardly defensible; indeed such acts are themselves instruments of colonization [Smith, 2012], so indigenist scholars in all fields seek to discuss cultures in their own terms. In neither case would it be uncontroversial to apply a recent, Western category like 'science communication' rootlessly and transcendently across the board. 
Nonetheless, for many science communicators, times and places beyond the recent West remain of potential interest. They are interested in any and all of the diverse human knowledge systems that included attention to the non-human world, knowledges that the Anglophone West today might call 'science', even if local actors would not have called them that or necessarily distinguished between 'human' and 'non-human' worlds. They are interested in interactions between people seen to be knowers of such knowledges and people seen as less knowledgeable. And they are interested in how those communicating about this material adapted communication practices for different contexts.

In other words, notwithstanding historians' and cross-cultural researchers' legitimate concerns, some science communicators are interested in practices throughout global history that, in non-trivial ways, were in some sense similar to science communication as we now practice it. Since prioritizing present-day inclusion and cultural relevance may be more important than concerns about anachronism and universalization, many would like any big picture, longue durée history of science communication to be bigger than the West and longer than the past two or three hundred years.

Historians in the 'popular science' area have generally shed doubt on such a possibility. Bensaude-Vincent [2009] and Topham [2009a] encouraged bigger picture historical research, but cautioned against conflating other practices with popular science or science popularization history as such. Secord [2004] influentially encouraged historical attention to all forms of what he termed 'knowledge in transit', meaning all the ways in which ideas and knowledge circulate. But he questioned whether a coherent history of something like science communication is possible, writing, "Popular science" is not a thing that comes into being at a particular moment or period; it is not appropriately seen as an emergent category' (670). While this seems to contradict Bensaude-Vincent's [2009] and Topham's [2009b] historicization of this concept, Secord's theorization is similarly focused on the relatively recent West, since all his examples are from Western Europe and North America in the past 500 years. In either case, there is only marginal space for recognizing something like 'science communication in eleventh century Song China' or 'science communication among the Yorta Yorta's ancestors 30,000 $\mathrm{YBP}^{\prime}$ in a way that meaningfully links them with global science communication practice today. Yet those are the kinds of topics some science communicators are interested in, and would like to see this discipline and profession engage with more actively and deeply. As it stands, historiographic norms cloud that possibility.

The racial politics of 'science' and reclaiming history for the present
There is a parallel here with demarcating the periods and cultures appropriate to study under the banner 'science history'. In a landmark work, Cunningham and Williams [1993] argued the word 'science' should only be used to label one specific approach to knowledge: the one that originated in the West around 1800 and was first branded with the English word 'science' in its current narrow sense. One of their guiding aims was to differentiate 'science' from the natural philosophy of early modern Europe. More broadly, they argued for decentring (modern, Western) science in terms of the multitude of human knowledge systems across the world and through time. They rejected the universalizing habits of twentieth century science historians who claimed every knowledge system in the world has been a 
part of the same endeavour. Instead, they argued each knowledge system is unique and should be judged by its own values.

Strictly historically speaking, their argument makes sense and is widely supported in the literature [reviewed by Orthia, 2016b]. Their decentring project is also consistent with anti-Eurocentric, decolonizing ideals [Chambers and Gillespie, 2000]. But pragmatically, there are political problems with their terminology proposal. Their restrictive use of 'science' does not account for the rhetorical privilege accorded the label in the world today. In writing about Ancient Babylonian astrology, Rochberg [2010, p. 262] raised the objection that if she was prevented from calling her subject matter 'science', it would inevitably be categorized among the illegitimate 'others' of science - pseudoscience, religion, irrationalism, superstition - thus 'miscategorizing ancient investigations of phenomena and ancient bodies of "natural" knowledge as unjustified or wrong belief.' As Giglioni [2007, p. 663] noted, this insistence on historical terminological precision 'amounts to saying that nineteenth-century science is the reference point for historians of science who wish to establish what science is. To say this is to say that science is, after all, what positivism said it was.' In other words, despite decolonizing ideals and historians' best efforts, labelling something 'science' (or withholding the label) carries a value judgement with great political resonance, both within and beyond the academy.

This becomes clear in debates about whether indigenous knowledges should be considered 'science'. A stark instance of an argument against this proposition is the 'Indigenous science' page on RationalWiki, a Wiki whose stated aims include refuting the anti-science movement. The culture of RationalWiki is in some ways anti-racist, for example, at the time of writing the wiki's authors classified 'racialism' as 'pseudoscientific bullshit' [RationalWiki contributors, 2019]. However, the 'Indigenous science' page reveals the scientistic limits of this anti-racism. It classified indigenous science (singular) as 'a pseudoscience' that 'should not be confused with legitimate research about indigenous people and their worldviews, such as in anthropology' [RationalWiki contributors, 2018]. It asserted that the view of some Western-trained Australian Indigenous scientists that Indigenous knowledge is science is 'unsupportable' [Australian Science Media Centre, 2018; RationalWiki contributors, 2018]. This is Eurocentric gatekeeping by Western science's advocates, and hardly the sole such example [e.g. Hikuroa, 2017; Nhalevilo, 2013; Nicholas, 2019]. Notwithstanding some indigenous peoples' reservations about eliding distinctions between indigenous knowledges and Western science (discussed in section 4 below), it demonstrates the power of conferring the word 'science' upon anything. This is an important strategic reason some Indigenous scientists describe themselves using terms such as 'STEMoriginal' [Moggridge, 2018] or assert that Indigenous Australians were the world's first scientists [de Napoli, 2018; Diamond, 2019], while at the same time maintaining distinct identities for Indigenous and Western sciences.

Ideally the word 'science' would not carry such rhetorical power. But pragmatically, we have a choice: let it remain a Eurocentric tool of exclusion, or reclaim it within a more inclusive vision. Arguably, the word's political power is more pressing than concerns about historical or cross-cultural terminological precision. This does not mean ignoring historical and cross-cultural questions. It means acknowledging they do not exist in a political vacuum, and negotiating the way forward with attention to contextual complexity. 
The same tension arises for the term 'science communication'. In the present-day, using it may carry value judgements too, partly because of its association with science, but also because of science communication's increasing legitimacy as a discipline and profession. If we are to (critically, cautiously) apply the word 'science' to knowledges beyond the recent West, we must consider opening 'science communication' to practices beyond it too. Certainly, indigenous peoples increasingly seek recognition of their knowledges within science communication endeavours, as discussed in section 1 above [see also Longnecker and Scott, 2018]. To persuade science communication's current, global community of practitioners, professionals, students, researchers, teachers and interested people that their history lies only in British natural history magazines and Parisian street electricity demonstrations would perpetuate Eurocentric marginalization within the discipline.

In contrast, reconfiguring 'science communication' in pluralist terms makes room for recognition of, and engagement with, diverse knowledge systems. To the extent that 'science communication' is today a desirable endeavour to be part of, with power, knowledges and skills of relevance to many, science communicators must take steps to radically reform their understandings of it so that people from diverse cultures, nations and traditions can genuinely own it as theirs. As Dawson [2019, p. 131] argues, while it is important to foster the potential for extremely novel, radically different ways of doing things, reform or 'detox' of science communication's firmly established institutions and practices is just as important.

Of course, individual science communicators could simply make their own choices about what is in and out of a museum exhibition or university syllabus. However, such pursuits warrant recognition and legitimacy for the reasons Dawson [2019] details, so questions about the cultural politics of science communication must become part of mainstream discourse in the discipline, rather than remaining marginalized and individualized.

The imperialistic risk of amalgamating diverse knowledge systems
There is a significant counterargument to this view. Never mind anachronism; some would consider it imperialistic and Eurocentric to claim 30,000 YBP Yorta Yorta and eleventh century Chinese histories in the name of 'science communication'. A parallel debate has raged within science education for decades. As Nhalevilo [2013, p. 29] cautions re including indigenous knowledges within school science curricula, even with good intentions such a move is neo-colonialist if the 'structures and philosophies [that] maintain Western science' do not also change, and therefore the indigenous discourse in which indigenous knowledge is embedded is missing [see also Gondwe and Longnecker, 2015b; Morrison et al., 2019]. Simpson [2004] eloquently argues that excising indigenous knowledge from its culture, language, place and people unavoidably damages its integrity, therefore it can only be maintained within that rich context. Thus, people interested in maintaining indigenous knowledge should first side with indigenous people in fights for self-determination and decolonization.

These arguments apply equally to communication conventions as to other kinds of knowledge and skill. Therefore, superficially incorporating culturally diverse snippets of history into the same Eurocentric, Western-triumphalist narrative would be culturally imperialistic and counter-productive to dismantling exclusivity. This approach is surprisingly common in university courses on world 
history [Conrad, 2019; see also Delbourgo, 2019]. It falls within the five characteristics of Eurocentric world histories that Conrad [2019, p. 5] describes, the five being: they (1) separate nature from humans, (2) centre (and do not racialize) Europeans while marginalizing everyone else, (3) uphold narratives of universal progress and associated ideas about European/Western superiority, (4) normalize the West as a uniquely coherent and exceptional entity, and (5) obscure violence and resistance associated with colonialism and related phenomena. A major risk for science communication history is that a single narrative would likely privilege the present-day, global-but-Western-inflected version of science communication which many science communicators are currently engaged in. That privileging may take the form of focusing more on the well-studied cultures of Europe and the West and treating others tokenistically (Conrad's point 2). This, in fact, reflects the current situation in this field, as discussed in section 2 above. It is pertinent to my circumstance: while the Australian university course that prompted this study did question Eurocentric values in this body of historical work, it still focused primarily on Europe and the West, especially in the nineteenth century, because they are well-studied. Having grappled with these issues, I intend to change this when the course next runs.

Related to this, Eurocentric histories frequently treat non-European and non-Western peoples as belonging to the past and unchanged through history, in contrast to Westerners who are seen to have developed into modern peoples and to be definitionally tied to the modern [Chakrabarty, 2000; Fabian, 2014; Gondwe and Longnecker, 2015a; Gondwe and Longnecker, 2015b]. This is especially the case for colonized indigenous peoples the world over (Conrad's points 3, 4 and 5), and is consistent with the notion that 'non-European histories [are] relevant to a global audience only after colonized peoples have created post-colonial forms and nation states' [Conrad, 2019, p. 5]. Science and science communication history are not exempt from this pattern. For example, in an iconic collection about Australian science history, the (single) chapter about Indigenous / Aboriginal conceptions of nature [Hiatt and Jones, 1988] used present-day anthropological material from Central Australia and Arnhem Land as a proxy for (continent-wide) historical data, as if Indigenous cultures have been uniform across time and place. Confusingly, the authors provided commentary about Indigenous cultures in the past tense, as if they were extinct and the Aranda, Gidjingarli and Rritharrngu informants mere relicts. Their multi-layered Eurocentrism came to the fore when, despite extensively documenting Indigenous people's technology and knowledge of nature, the authors concluded 'pre-European Australia' lacked 'a scientific tradition' [Hiatt and Jones, 1988, p. 19]. Their final sentence demonstrates how severely Eurocentrism distorts our tellings of science and science communication history: 'Although Australians of the future may not remember the indigenous inhabitants for their contributions to science, we can be sure that they will always contemplate with wonder and admiration the unique vision of nature enshrined in their art' [Hiatt and Jones, 1988, p. 19].

This is the kind of 'history' we must challenge, on all fronts. Being written with seemingly minimal input by Indigenous people (except as informant-subjects), it reproduced several Eurocentric pitfalls. One is the excision of knowledge from its context to be evaluated by the normative criteria of another system. Another is the relegation of this knowledge to an irrelevant past, implying the knowledge system is substandard, even primitive. Together, these comprise precisely what Simpson 
[2004], Nhalevilo [2013] and Morrison et al. [2019] warn against: the knowledge's integrity is questioned and potentially more prone to being lost because it is considered inferior and irrelevant by members of the dominant culture.

Does this mean an understanding of such knowledges should never be brought into the mainstream discourse of a discipline like science communication? At the very least, it demands caution in making such a move. But I suggest that move should be made, albeit with strict caveats. Bringing this greater breadth of vision within the umbrella of science communication history would not necessarily entail science communication making an imperialistic claim on global peoples. Instead, if attempted cautiously and critically, with Indigenous and other non-Western voices directing the endeavour along with allies, it could broaden the imaginary of who (which people, cultures, knowledges, ideas, practices) can make a claim on science communication. It cannot be a matter of Western/European science communicators turning a Western scientific gaze on non-Western cultures. It must instead be a matter of enriching science communication research and practice with a multitude of voices from many cultures, to challenge the received idea of what this discipline is and could be.

For that to actually occur, the discipline's many institutions would need to take material steps to ensure remunerated (paid, esteemed, empowered, continuing) positions are genuinely accessible to geoculturally diverse people, in large numbers. In Smith's [2012] influential work on this topic, she notes decolonizing research entails (among other things) indigenous researchers leading research about themselves, determining what kinds of questions are asked and having control over how knowledge is represented in academic and other outputs. This implies diverse indigenous and non-Western researchers will need funding if understandings of the world's diverse cultures are to be incorporated into science communication histories. It also implies such histories cannot be written without the perspectives, enthusiastic consent and control of the people being written about.

This would only be a sustainable solution if science communication culture also changes in radical ways to be vastly less exclusive [Dawson, 2019]. And changing the culture requires diverse people to be positioned within the culture. In other words, this process of institutional detox is iterative. Therefore, it must start somewhere and needs to start now. As Dawson [2019] contends, those already established in the discipline have a responsibility to start making such changes, trialling new approaches to science communication with the intention of dismantling the infrastructure of exclusivity. Reframing science communicators' sense of their own history in more cross-culturally cognizant ways, while simultaneously cultivating an attitude of 'cultural humility' [Morrison et al., 2019], would contribute to opening doors (and destroying buildings) so that currently marginalized people will count more, feel more welcome, be more represented, and be able to take and maintain power within science communication, and continue making change in the directions they see fit. 
Historicizing new approaches to science communication
To think about and practice science communication in these new ways in the present, it is likely necessary to think about history in a different way than Western-trained people are used to, to avoid the tyranny of historicism that frequently accompanies Eurocentrism. Chakrabarty [2000, p. 6] describes historicism as 'the idea that to understand anything it has to be seen both as a unity and in its historical development.' There are thus at least two moves necessary here.

Move 1: Disentangle elements of present-day science communication. First, we must think about science communication as a set of practices with something in common rather than a single, unified endeavour. Multiple elements of present-day science communication are frequently intertwined in practice but are not inherently related. For example, three (of many) possible aims of science communication are: (1) to disseminate uncontested science-related information to people who need or want it using diverse, audience-appropriate mediums; (2) to promote a Western scientific way of solving problems above other modes of thought; and (3) to encourage public deliberation about the appropriate place of new knowledge and technologies in society. Some of these aims are more controversial than others in current science communication scholarship, yet they may also be conflated in some science communicators' ideas about their field [Metcalfe, 2019]. That must change. We must separate them in our thinking, if we are to enable a bigger vision of science communication history. Each has different histories, and these can be teased out as some scholars have begun to do [e.g. Bensaude Vincent, 2001; Leach, 2013]. In the Western tradition, we might date the third aim to the late French Enlightenment [Orthia, 2016a] and the second to seventeenth century Britain [Meyer, 2016]. The first is much older and more cross-culturally inflected (see below). After their various origin points, each faced different trajectories, disappearing and reappearing in public and scientific discourse. By tracing those histories and understanding their whos, whats, whens, wheres and hows, as well as their intersections and differentiations and similar but not genealogically linked instances across time and space, we can better understand them. We can also separate them out from some essentialist notion of 'science communication' based on present day dominant trends.

Regarding the origins of the first aim: seen from a Western perspective and tracing it genealogically from the present day, we can surely track this kind of practice back at least 1500 years and probably much longer, throughout many cultures across the Afro-Asian landmass and surrounding islands. Hobson [2004; 2015] has shown how trade networks centred on the 'Islamic Bridge of the World' in the Middle East and North Africa - networks stretching from East Asia to West Africa, from the Southern Ocean to the Arctic - connected diverse peoples within an economy that covered half the globe [for a Pacific-centred view, see Matsuda, 2012]. This enabled extensive cross-cultural diffusion of what Hobson calls resource portfolios: ideas, technologies and institutions. As he shows, this trade network dominated human relations in much of the world between 600 and $1800 \mathrm{CE}$ and enabled the rise of the West to global economic power from the nineteenth century onwards. Hobson [2004] demonstrates in great detail the overwhelming influence 'Eastern' resource portfolios from China, Indonesia, India, Persia, Islamic North Africa and more had on European culture, including their foundational importance to historical moments such as the so-called Scientific Revolution. 
A longue durée, cross-cultural history of science communication should at least include much of this in its big picture. History of science and science and technology studies scholarship has acknowledged it to an extent, though more must be done to bring it into the mainstream [Delbourgo, 2019; Harding, 2011; Seth, 2017], and still more to bring it into the science communication realm. Looked at from one perspective, this semi-global trade network is one big, rich and longstanding example of science communication in action. We must be specific about what we mean by 'science communication' in any examples from this big picture, since any instance's contents, mediums, aims, interlocutors and contexts will be different from another's. Nonetheless, opening the framework of science communication history to give weight to the movement of ideas across Afro-Asia for more than a thousand years already opens our minds to alternative conceptions of what this discipline might be.

The few works in this tradition that discuss millennia-old Chinese communications about topics relevant to science are steps in this direction. In some cases it is a matter of refocusing on communicative aspects of works which twentieth century historians identified as 'science', such as the notebook encyclopedia Meng Hsi Pi $T^{\prime}$ 'an written by Shen Kua in Northern Song China between 1090 and 1095 CE [Shen, 2011]. The book is potentially of great interest to science communicators for its similarities to present-day science communication, such as, for example, its discussion of the merits of book-based versus experience-based expertise. Yet it is not usually considered a part of the science communication tradition, even within China where it is well known in other contexts. Countless other examples within Hobson's timeframe offer promise for a longue durée, cross-cultural history of science communication, but are yet to be developed for this purpose.

Move 2: Recognize multiple histories. That is the first move: disentangling component parts of 'science communication' and locating each in time, space and culture. The second move would take the big picture history out of this roughly genealogical model and single, 'global' chronology, because no matter how many older cultures it gives credit to, it still risks falling into a Eurocentric narrative of all-roads-lead-to-Western-modernity. To avoid that, we must instead tease out multiple, simultaneous histories within the big picture. Hobson's [2004; 2015] narrative does much to counter Eurocentric world histories, but because it emphasizes questions relevant to global economic power, it remains centred on Africa, Asia and Europe. Peoples of Australasia, Oceania and the Americas do not enter his narrative until the moment Europeans encounter their lands [for partial exceptions, see Matsuda, 2012]. In addition, Hobson's focus still shifts to the West during the nineteenth and twentieth centuries because of his topic.

However, there are already published works by indigenous peoples from those places that could provide foundations for a multi-stranded portrait of global science communication histories. The Yorta Yorta example is a particularly enticing one because of its great age. The Yorta Yorta Nation is a group of peoples from the mid-upper Murray River (Dhungalla) region in Southeastern Australia [H. Atkinson, 2004; W. Atkinson, 2005]. Like other Indigenous peoples from the continent now known as Australia, the Yorta Yorta and their ancestors have occupied their lands for an extremely long time in the order of tens of millennia, or as they put it, since creation [W. Atkinson, 2005]. 
As mentioned in section 1 , a story about a specific geological event their ancestors witnessed 30,000 years ago has been passed through countless generations to present day Yorta Yorta people [hear or read the full story at Atkinson, Cardamone and King, 2016]. The event was the uplift of the Cadell Fault across the ancestral river, which eventually shifted the river's course and caused a large flood that created the wetland-forest ecosystem known as Barmah-Millewa [W. Atkinson, 2005]. Yorta Yorta ancestors witnessed the initial uplift event and the events that followed it over millennia, and documented their observations about its impact on the land, their commentary on the causes of changes, and their related actions, in the form of what a Yorta Yorta elder described in 2013 as both 'an oral history' and 'a 30,000-year-old story that's been handed down from generations to generations' [Atkinson, Cardamone and King, 2016]. While the existence of the story in the present-day demonstrates continuity of knowledge, a historical study of it may capture changes in communication practice and modifications to the content that must have taken place in response to the changing environment. Such a history has yet to be published - and will likely require further research and elaboration by Yorta Yorta researchers and knowledge keepers - but would be an informative thread of science communication history, speaking to dynamics of continuity and change. As elder and academic Wayne Atkinson [2005, p. 7] writes of the event's impacts, 'Traditional conventional mechanisms of land use and control would have adapted to accommodate for change and survival. Cultural continuity was the outcome.'

In recent times, the Yorta Yorta have diversified the story's presentation, audience and communication mode to serve different aims. One version is disseminated via internet video, filmed in locations connected to the historical events [Atkinson, Cardamone and King, 2016]. The story is also told to audiences present on country [Sheales, 2013]. Versions of this story and other Yorta Yorta knowledge about country have been presented in different genres and mediums, including testimony in court cases [H. Atkinson, 2004], presentations to scientific societies [W. Atkinson, 2005], self-published reports used to campaign for land justice [Yorta Yorta Clans Group Inc., 2003], and Geographic Information Systems software to support culturally appropriate management activities [Lynch et al., 2017]. This recent history itself is of potential interest to science communicators as a tale of adapting knowledge communication to context, among other things.

The Cadell Fault story is likely one of the oldest and longest continuing examples of science communication in the world. It sits in a broader context of very old knowledge of celestial and earthly phenomena being maintained and communicated by Indigenous Australian peoples from one generation to the next, in carefully planned and controlled ways [e.g. Fuller and Hamacher, 2017; Hamacher and Norris, 2011; Matchan et al., 2020; Nunn and Reid, 2016]. Yet, like Meng Hsi Pi T'an, the story is not currently recognized as a potential part of science communication history by the larger science communication community. If science communicators are willing to open up conceptions of their history to radical revision, and if the Yorta Yorta's knowledge keepers support parts of their history being integrated into science communication narratives, perhaps that can change.

This example demonstrates why, in thinking about big picture science communication history, we must have multiple foci, acknowledging that every people, place and culture has its own history, most of which continue to the present day. To flesh those big pictures out, science communication needs researchers, 
teachers and communicators who can research, write and talk about these histories. Where such people already exist, who know something of the history of diverse people, places and cultures and have the potential to formalize what they know and research further, they are not necessarily recognized as part of the science communication community and may or may not see themselves becoming part of it. They may be academics in other disciplines and/or knowledge keepers within their cultures.

Science communicators established in the discipline need to change their paradigms of what and who counts, and place greater value on actions that will genuinely foster this human diversity and diverse expertise within the discipline's sphere. To iteratively expand its horizons, science communicators need to see further, make cross-cultural connections of different kinds, open conversations and support new research in this domain.

References

Ampollini, I. (2018). '1773: France starts to discuss how to communicate risk'. Public Understanding of Science 27 (8), pp. 1003-1008. https://doi.org/10.1177/0963662518787570.

Atkinson, H. (2004). 'Yorta Yorta co-operative land management agreement: impact on the Yorta Yorta nation'. Indigenous Law Bulletin 6 (5), pp. 23-25. URL: http://www.austlii.edu.au/au/journals/IndigLawB/2004/56 .html.

Atkinson, S., Cardamone, M. and King, D. (2016). Uncle Sandy Atkinson tells the Cadell Fault story. Culture Victoria.

URL: https://cv.vic.gov.au/stories/aboriginal-culture/ganagan/unclesandy-atkinson-tells-the-cadell-fault-story/ (visited on 18th July 2019).

Atkinson, W. (2005). 'Yorta Yorta occupation and 'the search for common ground". Proceedings of the Royal Society of Victoria 117 (1), pp. 1-22.

Australian Science Media Centre (28th May 2018). Why is Indigenous science important? Australia's Science Channel. (Visited on 16th July 2019).

Ball, R. (2015). 'STEM the gap: science belongs to us mob too'. Australian Quarterly 86 (1), pp. 13-19.

Bensaude Vincent, B. (2001). 'A genealogy of the increasing gap between science and the public'. Public Understanding of Science 10 (1), pp. 99-113. https://doi.org/10.1088/0963-6625/10/1/307.

Bensaude-Vincent, B. and Blondel, C., eds. (2008). Science and spectacle in the European enlightenment. Aldershot, U.K.: Ashgate.

Bensaude-Vincent, B. (2009). 'A historical perspective on science and its "others"'. Isis 100 (2), pp. 359-368. https://doi.org/10.1086/599547.

Chakrabarty, D. (2000). Provincializing Europe: postcolonial thought and historical difference. Princeton, NJ, U.S.A.: Princeton University Press.

Chambers, D. W. and Gillespie, R. (2000). 'Locality in the history of science: colonial science, technoscience and indigenous knowledge'. Osiris 15, pp. 221-240. https://doi.org/10.1086/649328.

Conrad, J. (2019). 'The big history project and colonizing knowledges in world history curriculum'. Journal of Curriculum Studies 51 (1), pp. 1-20. https://doi.org/10.1080/00220272.2018.1493143.

Cunningham, A. and Williams, P. (1993). 'De-centring the 'big picture': the origins of modern science and the modern origins of science'. The British Journal for the History of Science 26 (4), pp. 407-432. https://doi.org/10.1017/s0007087400031447. 
Daum, A. W. (2009). 'Varieties of popular science and the transformations of public knowledge: some historical reflections'. Isis 100 (2), pp. 319-332. https://doi.org/10.1086/599550.

Dawson, E. (2019). Equity, exclusion and everyday science learning: the experiences of minoritised groups. London, U.K.: Routledge.

Dayé, C. (2018). 'A systematic view on the use of history for current debates in sociology and on the potential and problems of a historical epistemology of sociology'. The American Sociologist 49 (4), pp. 520-547. https://doi.org/10.1007/s12108-018-9385-1.

de Napoli, K. (8th December 2018). 'Indigenous astronomy to revitalise the Australian curriculum'. IndigenousX. URL: https://indigenousx.com.au/indig enous-astronomy-to-revitalise-the-australian-curriculum/ (visited on 8th August 2019).

Delbourgo, J. (2019). 'The knowing world: a new global history of science'. History of Science 57 (3), pp. 373-399. https: //doi .org/10.1177/0073275319831582.

Diamond, C. (5th August 2019). 'Young indigenous women invited to join STEM academy'. IndigenousX. URL: https://indigenousx.com.au/young-indigenous -women-invited-to-join-stem-academy/ (visited on 8th August 2019).

Fabian, J. (2014). Time and the other: how anthropology makes its object. Original publication year (1983). New York, NY, U.S.A.: Columbia University Press. https://doi.org/10.7312/fabi16926.

Fróes da Fonseca, M. R. (2017). 'La ciencia recreativa and the popularisation of science in Mexico in the 19th century'. JCOM 16 (03), A07. https://doi.org/10.22323/2.16030207.

Fuller, R. S. and Hamacher, D. W. (2017). 'Did Aboriginal Australians record a simultaneous eclipse and aurora in their oral traditions?' Journal of Astronomical History and Heritage 20 (3), pp. 349-359.

Giglioni, G. (2007). 'Irritating experiments: Haller's concept and the European controversy on irritability and sensibility, 1750-90 (review)'. Bulletin of the History of Medicine 81 (3), pp. 662-664. https://doi.org/10.1353/bhm.2007.0069.

Gil, S. (2018). 'An animated episode in the history of science: remembering Giordano Bruno beyond 1600'. Public Understanding of Science 27 (6), pp. 745-749. https://doi.org/10.1177/0963662518758522.

Gondwe, M. and Longnecker, N. (2015a). 'Objects as stimuli for exploring young people's views about cultural and scientific knowledge'. Science, Technology, $\mathcal{E}$ Human Values 40 (5), pp. 766-792. https://doi.org/10.1177/0162243915577452.

- (2015b). 'Scientific and cultural knowledge in intercultural science education: student perceptions of common ground'. Research in Science Education 45 (1), pp. 117-147. https://doi.org/10.1007/s11165-014-9416-z.

Govoni, P. (2009). 'The historiography of science popularization: reflections inspired by the Italian case'. In: Popularizing science and technology in the European periphery, 1800-2000. Ed. by F. Papanelopoulou, A. Nieto-Galan and E. Perdiguero. Farnham, U.K.: Ashgate, pp. 21-42. https://doi.org/10.4324/9781315601472.

Habermas, J. (1989). The structural transformation of the public sphere: an inquiry into a category of Bourgeois society. Original publication year (1962). Cambridge, MA, U.S.A.: Massachusetts Institute of Technology Press.

Hamacher, D. W. and Norris, R. P. (2011). 'Eclipses in Australian Aboriginal astronomy'. Journal of Astronomical History and Heritage 14 (2), pp. 103-114. 
Harding, S., ed. (2011). The postcolonial science and technology studies reader. Durham, NC, U.S.A.: Duke University Press.

Hiatt, L. R. and Jones, R. (1988). 'Aboriginal conceptions of the workings of nature'. In: Australian science in the making. Ed. by R. W. Home. Cambridge, U.K.: Cambridge University Press, pp. 1-22.

Hikuroa, D. (2017). 'Mātauranga Māori — the ūkaipō of knowledge in New Zealand'. Journal of the Royal Society of New Zealand 47 (1), pp. 5-10. https://doi.org/10.1080/03036758.2016.1252407.

Hobson, J. M. (2004). The eastern origins of western civilisation. Cambridge, U.K.: Cambridge University Press.

Hobson, J. M. (2015). 'The eastern origins of the rise of the west and the 'return' of Asia'. East Asia 32 (3), pp. 239-255. https://doi.org/10.1007/s12140-015-9229-3.

Huang, H.-F. (2016). 'When Urania meets Terpsichore: a theatrical turn for astronomy lectures in early nineteenth-century Britain'. History of Science 54 (1), pp. 45-70. https://doi.org/10.1177/0073275315624422.

Knight, D. (2006). Public understanding of science: a history of communicating scientific ideas. Abingdon, U.K.: Routledge.

Leach, J. (2013). 'Science communication'. In: The handbook of communication history. Ed. by P. Simonson, J. Peck, R. T. Craig and J. P. Jackson Jr. New York, NY, U.S.A. and Abingdon, U.K.: Routledge, pp. 289-301.

Longnecker, N. and Scott, C. (2018). 'Challenges of cross-cultural communication in production of a collaborative exhibition: Wai ora, Mauri ora'. JCOM 17 (04), C05. https://doi.org/10.22323/2.17040305.

Lynch, A. H., Griggs, D., Joachim, L., Salminen, E., Heider, C., Kestin, T., Zhu, X. and Veland, S. (2017). 'Challenges of diverse knowledge systems in landscape analysis of the Murray-Darling basin, Australia'. Regional Environmental Change 17 (3), pp. 767-776. https://doi .org/10.1007/s10113-016-1069-1.

Lynn, M. R. (2006). Popular science and public opinion in eighteenth-century France. Manchester, U.K.: Manchester University Press.

Massarani, L., Moreira, I. and Lewenstein, B. (2017). 'A historical kaleidoscope of public communication of science and technology'. JCOM 16 (03), E. https://doi.org/10.22323/2.16030501.

Matchan, E. L., Phillips, D., Jourdan, F. and Oostingh, K. (2020). ‘Early human occupation of southeastern Australia: new insights from ${ }^{40} \mathrm{Ar} /{ }^{39} \mathrm{Ar}$ dating of young volcanoes'. Geology. https://doi .org/10.1130/g47166.1.

Matsuda, M. K. (2012). Pacific worlds: a history of seas, peoples and cultures. Cambridge, U.K.: Cambridge University Press.

Mazzotti, M. (2004). 'Newton for ladies: gentility, gender and radical culture'. The British Journal for the History of Science 37 (2), pp. 119-146. https://doi.org/10.1017/s0007087404005400.

Metcalfe, J. (2019). 'Comparing science communication theory with practice: an assessment and critique using Australian data'. Public Understanding of Science 28 (4), pp. 382-400. https://doi .org/10.1177/0963662518821022.

Meyer, G. (2016). 'In science communication, why does the idea of a public deficit always return?' Public Understanding of Science 25 (4), pp. 433-446. https://doi.org/10.1177/0963662516629747.

Moggridge, B. (10th January 2018). 'From STEM to stern'. The Walkley Magazine. URL: https://medium.com/the-walkley-magazine/from-stem-to-stern-db33 bc1e3897. 
Mori, J. C. (2016). 'Popular science in eighteenth century almanacs: the editorial career of Henry Andrews of Royston, 1780-1820'. History of Science 54 (1), pp. 19-44. https://doi.org/10.1177/0073275315625410.

Morrison, A., Rigney, L.-I., Hattam, R. and Diplock, A. (2019). Toward an Australian culturally responsive pedagogy: a narrative review of the literature. Adelaide, SA, Australia: University of South Australia.

Nhalevilo, E. Z. d. F. A. (2013). 'Rethinking the history of inclusion of IKS in school curricula: endeavoring to legitimate the subject'. International Journal of Science and Mathematics Education 11 (1), pp. 23-42. https://doi.org/10.1007/s10763-012-9382-8.

Nicholas, G. (19th February 2019). 'An uneasy alliance: indigenous traditional knowledge enriches science'. The Conversation.

URL: https://theconversation.com/an-uneasy-alliance-indigenous-tradi tional-knowledge-enriches-science-109212 (visited on 16th July 2019).

Nunn, P. D. and Reid, N. J. (2016). 'Aboriginal memories of inundation of the Australian coast dating from more than 7000 years ago'. Australian Geographer 47 (1), pp. 11-47. https://doi.org/10.1080/00049182.2015.1077539.

Orthia, L. A. (2016a). 'Democratizing science in the eighteenth century: resonances between Condorcet's Sketch (1795) and twenty-first century science communication'. JCOM 15 (04), A04. https://doi .org/10.22323/2.15040204.

- (2016b). 'What's wrong with talking about the scientific revolution? Applying lessons from history of science to applied fields of science studies'. Minerva 54 (3), pp. 353-373. https://doi .org/10.1007/s11024-016-9299-4.

Pandora, K. (2009). 'Popular science in national and transnational perspective: suggestions from the American context'. Isis 100 (2), pp. 346-358. https://doi.org/10.1086/599548.

Papanelopoulou, F., Nieto-Galan, A. and Perdiguero, E., eds. (2009). Popularizing science and technology in the European periphery, 1800-2000. Farnham, U.K.: Ashgate.

Perera, S. (2014). 'Is post-compulsory science a study option for everyone? Findings from an innovative science programme for young humanitarian immigrants in Australia'. STEMPlanet Journal 1 (1).

RationalWiki contributors (29th October 2018). Indigenous science. RationalWiki. URL: https://rationalwiki.org/wiki/Indigenous_science (visited on 16th July 2019).

- (28th July 2019). Racialism. RationalWiki. URL: https: //rationalwiki.org/wiki/Racialism (visited on 29th July 2019).

Rauchfleisch, A. and Schäfer, M. S. (2018). 'Structure and development of science communication research: co-citation analysis of a developing field'. JCOM 17 (03), A07. https://doi .org/10.22323/2.17030207.

Raza, G. and Singh, S. (2009). 'Cultural distance and science communication: few lessons from the past and present'. Contemporary Perspectives 3 (2), pp. 310-336. https://doi.org/10.1177/223080750900300206.

Rochberg, F. (2010). 'Beyond binarism in Babylon'. Interdisciplinary Science Reviews 35 (3-4), pp. 253-265. https: //doi.org/10.1179/030801810x12772143410043.

Secord, J. A. (2004). ‘Knowledge in transit'. ISIS 95 (4), pp. 654-672. https://doi.org/10.1086/430657. PMID: 16011300.

Seth, S. (2017). 'Colonial history and postcolonial science studies'. Radical History Review 2017 (127), pp. 63-85. https : //doi . org/10.1215/01636545-3690882. 
Sheales, R. (24th February 2013). Visions: on country learning. The University of Melbourne YouTube channel.

URL: https://www youtube. com/watch?v=-ep08IUSd5Q\&t=8s (visited on 29th July 2019).

Sheets-Pyenson, S. (1985). 'Popular science periodicals in Paris and London: the emergence of a low scientific culture, 1820-1875'. Annals of Science 42 (6), pp. 549-572. https://doi.org/10.1080/00033798500200361.

Shen, K. (2011). Brush talks from dream brook. H. Wang and Z. Zhao translators. Chengdu, China: Sichuan People's Publishing House and Paths International.

Simpson, L. R. (2004). 'Anticolonial strategies for the recovery and maintenance of indigenous knowledge'. The American Indian Quarterly 28 (3), pp. 373-384. https://doi.org/10.1353/aiq.2004.0107.

Smith, L. T. (2012). Decolonizing methodologies: research and indigenous peoples. 2nd ed. London, U.K.: Zed Books.

Topham, J. R. (2009a). 'Rethinking the history of science popularization/popular science'. In: Popularizing science and technology in the European periphery, 1800-2000. Ed. by F. Papanelopoulou, A. Nieto-Galan and E. Perdiguero. Farnham, U.K.: Ashgate, pp. 1-20.

Topham, J. R. (2009b). 'Introduction to focus: historicizing 'popular science". Isis 100 (2), pp. 310-318. https://doi.org/10.1086/599551.

Yorta Yorta Clans Group Inc. (11th January 2003). Management plan for Yorta Yorta cultural environmental heritage project. URL: https://waynera.files . wordpre ss.com/2010/10/finalreportlandman.pdf.

Author

Lindy A. Orthia is a senior lecturer in science communication at the Centre for the Public Awareness of Science (CPAS), the Australian National University. Her research interests include history of science communication, science in popular fiction, and the intersections of science with sociopolitical identifiers such as race, gender and sexual orientation. E-mail: lindy.orthia@anu.edu.au.

\section{How to cite}

Orthia, L. A. (2020). 'Strategies for including communication of non-Western and indigenous knowledges in science communication histories'. JCOM 19 (02), A02. https:/ / doi.org/10.22323/2.19020202. 